Journal of
Nutrigenetics
Nutrigenomics
J Nutrigenet Nutrigenomics 2014;7:153-160 (c) 2015 S. Karger AG, Basel

1661-6499/15/0073-0153\$39.50/0

www.karger.com/jnn

\title{
Review
}

\section{Prescribing Personalized Nutrition for Cardiovascular Health: Are We Ready?}

\author{
Shanil Juma Victorine Imrhan Parakat Vijayagopal Chandan Prasad \\ Department of Nutrition and Food Sciences, Texas Woman's University, Denton, Tex., USA
}

\section{Key Words}

Diet · Cardiovascular disease $\cdot$ Genes · Nutrition

\begin{abstract}
Of all chronic metabolic diseases, cardiovascular disease (CVD) is the leading cause of death worldwide. Most research over the past 100 years show a link between CVD and lifestyle, including diet; thus, public health messages have focused on modifications of the diet to better manage this disease. Despite this effort, the CVD mortality rate continues to rise. Therefore, is it possible that this failure may be due to individual variability in response to dietary recommendations? The elucidation of the structure of the human genome combined with the knowledge that nutrients are capable of modifying gene expression and genetic variability regulates how individuals respond to a diet have led to the possibility of personalized nutrition for disease prevention. While this possibility is real for the future, our current understanding of nutrient-gene interactions for CVD is limited, making personalized nutrition therapy difficult at this time. With advances in nutritional genomics, in the near future, dietitians and nutritionists will be able to give personalized nutritional advice based on a combination of lifestyle factors and genetics.

(C) 2015 S. Karger AG, Basel
\end{abstract}

\section{Introduction}

Cardiovascular disease (CVD), commonly known as heart disease, includes a variety of disease conditions affecting the heart and blood vessels (arteries, capillaries, and veins). Our long-term population-based observations have suggested an association between the risk for CVD and abdominal obesity and abnormal lipid profiles. Therefore, nutrition counseling for the prevention of CVD has largely focused on weight reduction and normalization of lipid profiles through diet, exercise, and medication. In randomized placebo-controlled clinical 
Juma et al.: Prescribing Personalized Nutrition for Cardiovascular Health: Are We Ready?

trials, aggressive modification of these risk factors for CVD has yielded a 30-40\% reduction in mortality and morbidity [1-4]. Epidemiologic, familial, and twin studies have suggested a strong genetic predisposition for CVD [5]. Support for this has come from multiple sources. For example, data from the Framingham Study [6] have shown that a family history of CVD or stroke is associated with a greater than 2.2-2.4-fold increase in the risk for CVD. This risk was further heightened by $2-3$-fold in first-degree relatives [7, 8]. Additional support for this conclusion has come from multiple other studies [9-11].

The sequencing of the human genome in $2001[12,13]$ brought a flurry of hope for designer diets based on the genetic makeup for the prevention of CVD. This hope was further heightened by the demonstration of an association between an increasing number of variants of select target genes and the risk for CVD [14-16]. The list of such variants continues to grow with genome-wide association studies (GWAS). While the potential of an important role for genetic testing in appropriate nutrition counseling for the prevention of CVD is there, we are not yet scientifically ready for this. The public interest and impatience in getting access to a product and/or service that may reduce the risk for CVD have led to multiple commercial ventures that include nutrition counseling and offer of products throughout the world. This has led US regulatory agencies to take legal steps to control many such services [17-20]. At least a decade before the sequencing of the human genome $[12,13]$ that led to an explosion of hope for genetics-based nutrition counseling, we already knew about the existence of reciprocal relationships between nutrients and genes. This had resulted from our attempt to get a logical answer to 2 questions. First, why do some individuals who consume high-fat diets show no evidence of atherosclerotic disease like most others [21]? Second, why do Asians and Europeans respond differently to thiamin deficiency [22]? The logical answer at that time was a possible dependence of the physiologic response on gene-diet interactions. This, indeed, was the birth of the concept of nutrigenomics. Today, in the published literature one finds many different terminologies (nutrigenomics, nutrigenetics, nutritional genomics, or nutritional genetics) defining the reciprocal relationship between nutrients and genes. Few years ago, DeBusk et al. [23] proposed the terms 'nutritional genomics' to define the 'study of the effects of ingested nutrients and other food components on gene expression and gene regulation' and 'nutritional genetics' to define the 'identification of human genetic variations that are the cause of differences in phenotypic responses to diets among humans'. The purpose of this review is to critically evaluate the science and the level of our readiness for geneticsbased nutrition advice for the prevention of CVD.

\section{Nutrition Prescription/Counseling: A Historical Survey}

The role of nutrition in health has been well documented in the writings of Ayurvedic and Chinese medicine some 3,000 years ago. For example, a prescription of individualized diet, exercise, and lifestyle recommendations was always included in any patient care plan prescribed by Ayurvedic physicians (Vaidyas). This was no different in Chinese medicine practice. Hippocrates (460-375 BC), the Greek physician regarded as the father of modern medicine, placed great emphasis on nutrition in both the prevention and treatment of diseases. While the concept that diet is an important element in the prevention and treatment of diseases was firmly established during the Naturalistic Era (from 400 BC to 1750 AD), dietetics or nutrition education showed little progress until advances were made in chemistry and physiology during the Chemical-Analytical Era (1750-1900). This period brought an understanding of food composition. The start of the 1900s was the beginning of the Biologic Era that gave us a better understanding of the metabolic pathways as well as the role of macronutrients and micronutrients in health [24]. The link between nutrition and 
diseases such as rickets, scurvy, and CVD was noted. Understanding that certain vitamins and nutrients can prevent diseases was a breakthrough for medicine. This also coincided with the founding of the American Dietetic Association (now the Academy of Nutrition and Dietetics).

Toward the end of World War II, 2 landmark studies were started. Allbaugh [25] reported that the diet in Greece was adequate and only a limited number of residents had nutritional deficiencies. However, Keys [26] observed a relationship between food shortages and a lower incidence of coronary artery disease (CAD) in northern Europe. This observation led to the Seven Countries Study (1957), which showed that societies where the diet was high in fat (Finland and USA) had higher blood cholesterol levels and deaths by heart attack than those where the diets consisted of fresh fruits and vegetables along with pasta and olive oil (Mediterranean region). Thus, preventive efforts shifted to entire populations rather than high-risk individuals $[27,28]$.

By the later part of the 20th century, the prevention or even reversal of CVD in a population by eating the right balance of nutrients was a widely accepted concept. Ornish et al. [29] published their landmark study in the 1990 issue of the Lancet, which reported that participants who made lifestyle changes and followed strict dietary rules saw a reversal in even severe coronary atherosclerosis. In the following years, there was a huge growth in our mechanistic understanding of as well as empirical knowledge about the relationship between diet, dietary components, and disease, largely through epidemiologic investigations. The information gathered in these population-based observations has been the basis for nutrition education and counseling. However, many of these epidemiologic studies examining the relationships between diet and disease have led to unsolved puzzles, suggesting 'one size does not fit all'. While there was no accepted answer to this puzzle at that time, a possible dependence of the physiologic response on gene-diet interactions seemed logical. As time passed, both interventional and epidemiologic studies made it very apparent that individuals respond differently to drugs, diets, and dietary components both between and within races or genders.

\section{Complexity of the Etiology of CVD}

CVD includes a variety of disease conditions affecting the heart and blood vessels (arteries, capillaries, and veins). These commonly include CAD, atherosclerotic heart disease, coronary heart disease, and ischemic heart disease where plaques along the inner walls of arteries lead to heart attacks. While gender, age, and genetics are immutable risk factors for CVD, modifiable risk factors play a major role in the causation and progression of the disease. The modifiable risk factors include hypertension, hyperlipidemia, obesity, diabetes, and smoking, to name a few. Based on the complexity of the etiology of CVD outlined here, one can easily appreciate the difficulties associated with any generic dietary recommendation for CVD prevention. Figure 1 summarizes a variety of modifiable and nonmodifiable risk factors that may play a causative role in CVD.

\section{Mapping of the Human Genome Has Brought an Explosion of Hope and Need for New Understandings of the Complexities of Gene-Diet Interactions}

The National Human Genome Research Institute and Celera completed the sequencing of the human genome almost simultaneously in 2001. To the surprise of all, the final sequence yielded approximately 23,000 protein-coding genes instead of 80,000 to 100,000 that were 
Journal of

Nutrigenetics

Nutrigenomics

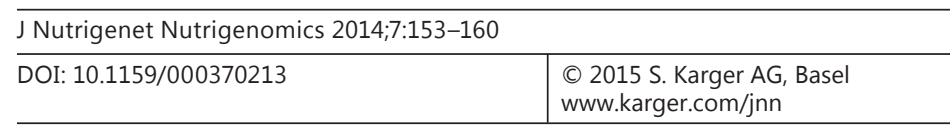

Juma et al.: Prescribing Personalized Nutrition for Cardiovascular Health: Are We Ready?

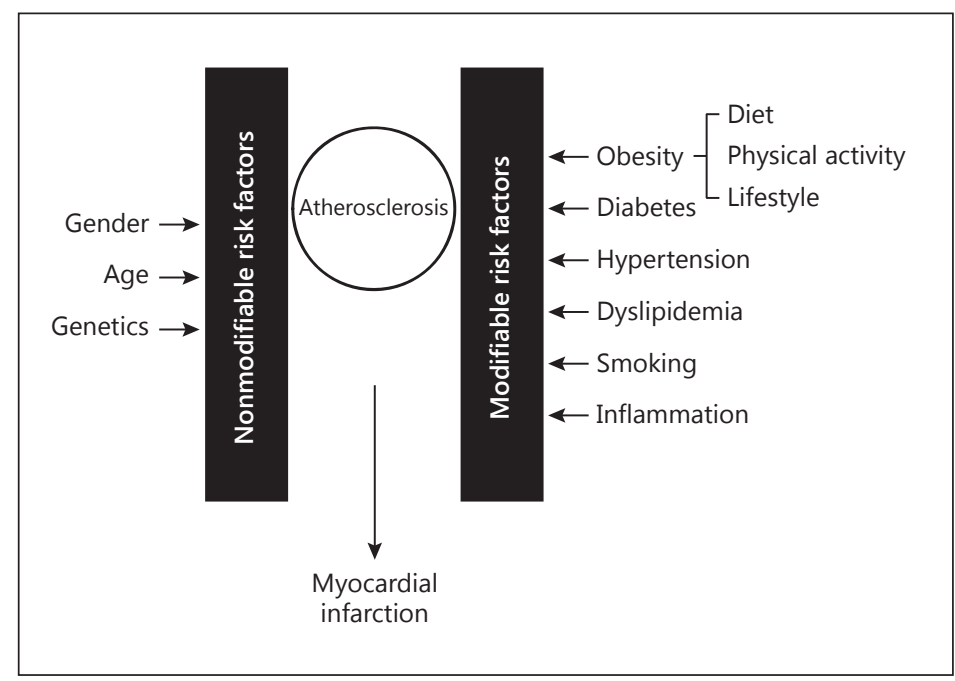

Fig. 1. Modifiable and nonmodifiable risk factors associated with CVD.

expected. This amounts to only about $1.5 \%$ of the genome coding for proteins and the rest has unknown functions.

The media saw the sequencing of the human genome as the ultimate victory and cure for all human suffering. The business saw this as a 'new gold rush' and tried to make legal claims on the human genome. In no time, it became obvious that 23,000 protein-coding genes alone could not run a complex human cell. Recent studies have shown that a substantial portion of the nonprotein-coding sequence is translated into RNA, suggesting unknown functions for the resulting transcripts. Our understanding of the role for the bulk of the nonprotein-coding sequence of the genome is just appearing.

The complexity of the control of cell function goes beyond genomics and protein-coding genes to include gene duplication, transcriptomics, metabolomics, proteomics, epigenomics, and nutritional genomics. Epigenetic processes modulate gene expression without changing the actual DNA sequence. It is well known that these processes lead to meiotically and mitotically heritable changes in gene expression and play an important role in defining the cell identity. These epigenetic modifications alter the accessibility of chromatin by methylation of DNA at CpG dinucleotides and by modification or rearrangement of nucleosomes. Changes in nucleosomes are brought about through covalent post-translational modifications of histone tails. In this way, the gene function is altered with no change in the DNA sequence. Epigenetic modifications of histone tails may include acetylation, methylation, ubiquitination, and SUMOylation of lysine residues, phosphorylation of serine residues, and methylation of arginines.

Acetylation-deacetylation-mediated changes in gene expression are brought about by a counterbalancing action of histone acetyltransferases (HATs) and histone deacetylases (HDACs). HATs acetylate histones by transferring an acetyl group to the 8721 portion of lysine residues resulting in an open modification of the chromatin structure leading to an enhanced accessibility of DNA to the basal transcription initiation machinery. Conversely, gene repression is mediated via HDACs, which remove acetyl groups and counteract the activity of HATs resulting in a closed chromatin structure. Since HATs and HDACs regulate the expression of multiple genes, they most likely play an important role in the multifactorial processes that lead to atherosclerosis and restenosis. The methylation of $\mathrm{CpG}$ dinucleotides is generally associated with an epigenetic silencing of the transcription. CpG sequences frequently occur at the transcriptional start site of active genes, with most clusters of CpGs 
Juma et al.: Prescribing Personalized Nutrition for Cardiovascular Health: Are We Ready?

being hypomethylated. The process of methylation is transient and cyclic, which adds another level of control over the transcription. The estrogen receptor-alpha (ER $\alpha$ ) protects against atherosclerosis due to its action as a growth suppressor, causing the smooth muscle cells to remain in a quiescent state [30]. Hypermethylation of the ER $\alpha$ promoter thus allows intimal smooth muscle cells to proliferate excessively and contribute to the development of atherosclerotic lesions [31].

\section{Quandary of Identifying Genetic Determinants of CVD}

The difficulties associated with identifying genetic determinants that may be predictive of CVD are multiple. The first and foremost challenge associated with CVD is its phenotypic and genetic heterogeneity. The clinical presentation of CVD may vary according to the origin and etiology of the condition and, therefore, may be associated with variable pathways. Given that multiple causal pathways lead to CVD, it is reasonable to predict multiple genetic determinants in the causation of the disease. The two specific examples below support the above contention. First, low plasma HDL cholesterol, a determinant of CVD, can result from variations in one or more genes controlling its synthesis and catabolism. Second, the transition from a stable coronary atherosclerotic plaque to an unstable plaque leading to myocardial infarction may result in a genetic variation in multiple genes that participate in inflammation and matrix degradation. The contribution of genetics in the etiology of complex diseases such as CVD is the sum total of small gene effects originating from multiple genes. Therefore, although the odds ratio for individual genes may be smaller, they have an additive compounding effect [32]. Another level of complexity is brought about by gene-gene and gene-environment interactions. For example, the enzymes serine hydroxymethyltransferase 1 (SHMT1) and methylenetetrahydrofolate reductase (MTHFR) regulate key reactions in folate-mediated one-carbon metabolism. While no association between the SHMT1 rs1979277 SNP alone and CVD could be found, in the presence of the SHMT1 rs1979277 TT genotype there was a highly significant interaction between two genotypes $(\mathrm{OR}=4.34,95 \% \mathrm{CI}=1.2-16.2 ; \mathrm{p}=0.049)$ [33]. Both smoking and circulating interleukin-18 (IL-18) have been suggested to be involved in the etiology of CVD. To examine the possible interaction between smoking and the IL-18 gene, Grisoni et al. [34] examined 5 SNPs capturing the common genetic variation of the IL-18 gene (tag SNPs) in five European prospective CVD cohorts including 1,933 cases and 1,938 noncases as part of the MORGAM Project. The data revealed that, while not a single SNP was found to be associated with CVD, one IL-18 tag SNP interacted with cigarette smoking to increase the risk of developing CVD.

Exceptions to the aforementioned examples are Mendelian disorders associated with CVD, such as familial hypercholesterolemia. For example, mutations in the ligand-binding domain of the apolipoprotein B100 [35], the LDL receptor gene (LDLR) [36], and the proprotein convertase subtilisin/kexin type 9 gene (PCSK9) [37] lead to familial hypercholesterolemia that is inherited in an autosomal manner. Several Mendelian disorders of lipid metabolism are associated with an elevated risk for CVD.

Recently, the search for genetic markers to help predict risks for CVD has been a very active area of investigation. Previous explorations of genetic determinants for CVD have focused on a candidate gene approach that is limited in scope. In recent years, with the advent of precise and rapid sequencing technology, it has become possible to perform GWAS on a large number of individuals without bias towards any particular candidate gene. This approach revealed a significant association between common variants on chromosome 9p21 and CVD [38]. While GWAS are an unbiased statistical approach to look for genetic markers capable of predicting the risk for CVD, there are many issues with the data collected so far 
Juma et al.: Prescribing Personalized Nutrition for Cardiovascular Health: Are We Ready?

making their use minimally effective. First, the genetic diversity in the human genome is much greater than initially predicted. About $0.5 \%$ of the total genome differs between individuals, and at least $44 \%$ of the annotated genes exhibit DNA sequence variation [39, 40]. Since GWAS have been conducted primarily in people with European descent, the information may be irrelevant for other ethnic groups. Second, many genetic loci conferring the risk for CVD have been found in regions without any known transcription or translation product. Therefore, it is difficult to ascertain the mechanism by which these loci participate in conferring the CVD risk. Third, GWAS have identified over three dozen genetic variants associated with an increased risk for CVD. The odds ratio for the CVD risk associated with any one variant was very low when compared with the heritable genetic component of the disease. It ranged from 1.06 to 1.92 , with a mean of $1.17 \pm 0.18[14,15]$.

\section{Conclusions}

While early observational and epidemiologic studies led to the recognition that dietary nutrients have profound effects on our physiology, it also became clear that individuals do not response to dietary nutrients in a similar fashion. This led to the interpretation that there may exist some kind of reciprocal relationship between genes and nutrients. Further exploration of gene-nutrient interactions with the hope for genetics-based personalized nutrition counseling became a real possibility with the sequencing of the human genome.

It is the nature of scientific discovery that it leads to more questions and more discoveries. Following this path, the sequencing of the human genome led to the realization of possible physiologic regulatory functions of nutrients through the modulation of elements beyond the genome - epigenome, transcriptome, and proteome. This made it obvious that performing epidemiologic studies in the absence of genetic and postgenetic effects of nutrients may lead to erroneous scientific conclusions and misinformed nutritional recommendations. This has brought opportunities for scientific enquiries and an immense hope for the future of nutrition counseling. To bring this hope to fruition, teamwork between disciplines such as nutrition, dietetics, genetics, biochemistry, and molecular biology is highly warranted. The future of new-generation nutrition counseling does not depend on the new technologies that we are amassing, but on the storage, management, and interpretation of the vast quantity of data at multiple levels.

In conclusion, nutrition in the 21 st century is poised to be an exciting and highly relevant field of research, as each new day is accompanied by advances in our understanding of how the interactions between lifestyle and genotypes contribute to health and disease, taking us one step closer to achieving the highly desirable goal of personalized nutrition prescription.

\section{Disclosure Statement}

The authors have no conflicts of interest to declare.

\section{References}

1 Kannel WB, Dawber TR, Kagan A, Revotskie N, Stokes J: Factors of risk in the development of coronary heart disease - six year follow-up experience: the Framingham Study. Ann Intern Med 1961;55:33-50.

$>2$ US Department of Health and Human Services: The Health Consequences of Smoking - 50 Years of Progress: A Report of the Surgeon General. Atlanta, US Department of Health and Human Services, Centers for Disease Control and Prevention, National Center for Chronic Disease Prevention and Health Promotion, Office on Smoking and Health, 2014. 


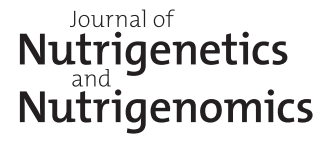

\begin{tabular}{l|l}
\hline J Nutrigenet Nutrigenomics 2014;7:153-160 \\
\hline DOI: $10.1159 / 000370213$ & $\begin{array}{l}\text { @ 2015 S. Karger AG, Basel } \\
\text { www.karger.com/jnn }\end{array}$ \\
\hline
\end{tabular}

Juma et al.: Prescribing Personalized Nutrition for Cardiovascular Health: Are We Ready?

3 Shepherd J, Cobbe SM, Ford I, Isles CG, Lorimer AR, et al: Prevention of coronary heart disease with pravastatin in men with hypercholesterolemia. West of Scotland Coronary Prevention Study Group. N Engl J Med 1995; 333:1301-1307.

4 Downs JR, Clearfield M, Weis S, Whitney E, Shapiro DR, et al: Primary prevention of acute coronary events with lovastatin in men and women with average cholesterol levels: results of AFCAPS/TexCAPS. Air Force/Texas Coronary Atherosclerosis Prevention Study. JAMA 1998;279:1615-1622.

-5 Chan L, Boerwinkle E: Gene-environment interactions and gene therapy in atherosclerosis. Cardiol Rev 1994; 2:130-137.

6 Schildkraut JM, Myers RH, Cupples LA, Kiely DK, Kannel WB: Coronary risk associated with age and sex of parental heart disease in the Framingham Study. Am J Cardiol 1989;64:555-559.

$\checkmark 7$ Colditz GA, Rimm EB, Giovannucci E, Stampfer MJ, Rosner B, et al: A prospective study of parental history of myocardial infarction and coronary artery disease in men. Am J Cardiol 1991;67:933-938.

-8 Hopkins PN, Williams RR, Kuida H, Stults BM, Hunt SC, et al: Family history as an independent risk factor for incident coronary artery disease in a high-risk cohort in Utah. Am J Cardiol 1988;62:703-707.

$\longrightarrow 9$ Rissanen A: Familial occurrence of coronary heart disease: effect of age at diagnosis. Am J Cardiol 1979;44: 60-66.

10 Allen G, Harvald B, Shields JP: Measures of twin concordance. Acta Genet Stat Med 1967;17:475-481.

11 Cooper JA, Miller GJ, Humphries SE: A comparison of the PROCAM and Framingham point-scoring systems for estimation of individual risk of coronary heart disease in the Second Northwick Park Heart Study. Atherosclerosis 2005; 181:93-100.

12 Lander ES, Linton LM, Birren B, Nusbaum C, Zody MC, et al; International Human Genome Sequencing Consortium: Initial sequencing and analysis of the human genome. Nature 2001;409:860-921.

13 Venter JC, Adams MD, Myers EW, Li PW, Mural RJ, et al: The sequence of the human genome. Science 2001; 291:1304-1350.

14 Roberts R, Stewart AFR: Genes and coronary artery disease: where are we? J Am Coll Cardiol 2012;60:17151721.

15 Roberts R, Stewart AFR: Genetics of coronary artery disease in the 21st century. Clin Cardiol 2012;35:536540.

16 Ioannidis JPA: Prediction of cardiovascular disease outcomes and established cardiovascular risk factors by genome-wide association markers. Circ Cardiovasc Genet 2009;2:7-15.

17 Kutz G; United States Government Accountability Office: Nutrigenetic Testing: Tests Purchased from Four Web Sites Mislead Consumers. Washington, US Government Accountability Office, 2006, pp 1-23.

18 Blum K, Chen TJH, Williams L, Chen ALC, Downs WB, et al: A short term pilot open label study to evaluate efficacy and safety of LG839, a customized DNA directed nutraceutical in obesity: exploring nutrigenomics. Gene Ther Mol Biol 2008;12:371-382.

19 Prasad C, Imrhan V, Rew M: Introducing nutritional genomics teaching in undergraduate dietetic curricula. J Nutrigenet Nutrigenomics 2011;4:165-172.

20 Downing NS, Ross JS: Innovation, risk, and patient empowerment: the FDA-mandated withdrawal of 23andMe's Personal Genome Service. JAMA 2014;311:793-794.

-21 Ye SQ, Kwiterovich PO Jr: Influence of genetic polymorphisms on responsiveness to dietary fat and cholesterol. Am J Clin Nutr 2000;72:1275S-1284S.

22 Boros LG: Population thiamine status and varying cancer rates between western, Asian and African countries. Anticancer Res 2000;20:2245-2248.

23 DeBusk RM, Fogarty CP, Ordovas JM, Kornman KS: Nutritional genomics in practice: where do we begin? J Am Diet Assoc 2005;105:589-598.

24 Carpenter KJ: A short history of nutritional sciences. Part 1 (1785-1885). J Nutr 2003;133:638-645.

25 Allbaugh LG: Crete: A Case Study of an Underdeveloped Area. Princeton, Princeton University Press, 1953.

26 Keys A (ed): Coronary heart disease in seven countries. Circulation 1970;41(Suppl):1-211.

27 Nestle M: Mediterranean diets: historical and research overviews. Am J Clin Nutr 1995;61:1313S-1320S.

28 Andrade J, Mohamed A, Frohlich J, Ignaszewski A: Ancel Keys and the lipid hypothesis: from early breakthroughs to current management of dyslipidemia. BCMJ 2009;51:66-72.

-29 Ornish D, Brown SE, Scherwitz LW, Billings JH, Armstrong WT, et al: Can lifestyle changes reverse coronary heart disease? The Lifestyle Heart Trial. Lancet 1990;336:129-133.

30 Dong C, Yoon W, Goldschmidt-Clermont PJ: DNA methylation and atherosclerosis. J Nutr 2002;132:2406S2409S.

-31 Yinga AK, Hassanaina HH, Roosa CM, Smiragliab DJ, Issac JPJ, et al: Methylation of the estrogen receptor- $\alpha$ gene promoter is selectively increased in proliferating human aortic smooth muscle cells. Cardiovasc Res 2000;46: 172-179.

-32 Risch NJ: Searching for genetic determinants in the new millennium. Nature 2000;405:847-856.

-33 Wernimont SM, Raiszadeh F, Stover PJ, Rimm EB, Hunter DJ, et al: Polymorphisms in serine hydroxymethyltransferase 1 and methylenetetrahydrofolate reductase interact to increase cardiovascular disease risk in humans. J Nutr 2011;141:255-260.

34 Grisoni ML, Proust C, Alanne M, DeSuremain M, Salomaa V, et al: Haplotypic analysis of tag SNPs of the interleukin-18 gene in relation to cardiovascular disease events: the MORGAM Project. Eur J Hum Genet 2008;16: 1512-1520. 


\section{Nutrigenomics}

\begin{tabular}{l|l}
\hline DOI: 10.1159/000370213 & $\begin{array}{l}\text { C } 2015 \text { S. Karger AG, Basel } \\
\text { www.karger.com/jnn }\end{array}$ \\
\hline $\begin{array}{l}\text { Juma et al.: Prescribing Personalized Nutrition for Cardiovascular Health: Are We } \\
\text { Ready? }\end{array}$
\end{tabular}

35 Pullinger CR, Hennessy LK, Chatterton JE, Liu W, Love JA, et al: Familial ligand-defective apolipoprotein B. Identification of a new mutation that decreases LDL receptor binding affinity. J Clin Invest 1995;95:12251234.

-36 Brown MS, Kovanen PT, Goldstein JL: Regulation of plasma cholesterol by lipoprotein receptors. Science 1981; 212:628-635.

-37 Tibolla G, Norata GD, Artali R, Meneghetti F, Catapano AL: Proprotein convertase subtilisin/kexin type 9 (PCSK9): from structure-function relation to therapeutic inhibition. Nutr Metab Cardiovasc Dis 2011;21:835843.

38 Ogawa N, Imai Y, Morita H, Nagai R: Genome-wide association study of coronary artery disease. Int J Hypertens 2010;2010:790539.

39 Levy S, Sutton G, Ng PC, Feuk L, Halpern AL, et al: The diploid genome sequence of an individual human. PLoS Biol 2007;5:e254.

40 Wheeler DA, Srinivasan M, Egholm M, Shen Y, Chen L, et al: The complete genome of an individual by massively parallel DNA sequencing. Nature 2008;452:872-876. 